\title{
Bronchial cast formation associated with loss of immunoglobulin and calcium
}

A 42-year-old Caucasian woman presented with dyspnoea and expectoration of white stringy phlegm with a consistency between goat's cheese and chewing gum (fig 1). She had had recurrent respiratory infections since childhood. In 1997 she noticed exertional dyspnoea and in 1999 she started producing bronchial casts. Pulmonary fibrosis was diagnosed based on a high-resolution CT scan which showed ground-glass opacities consistent with active early fibrosis. Prednisolone was started following an open lung biopsy which revealed bronchiolitis with peribronchial inflammation-associated fibrosis. Subsequent scans showed reduced alveolitis but progressive fibrosis. In 2004, tuberculosis was diagnosed on sputum culture and treated. Cultures have remained negative since. Azathioprine was introduced in 2005 and high-dose acetylcysteine was added in 2006. The patient started coughing up $250 \mathrm{ml}$ milky fluid daily when nebulisers with hypertonic saline were introduced in May 2006.

Her medication on admission included prednisolone, azathioprine, acetylcysteine and prophylactic isoniazid. There were bilateral inspiratory crackles. She required $6 \mathrm{l} / \mathrm{min}$ oxygen. Mild lung function impairment had recently been found during a less symptomatic period (forced expiratory volume in $1 \mathrm{~s} 2.131$ (74\%), inspiratory vital capacity 3.021 (88.7\%), total lung capacity 4.791 (93.9\%)). Total

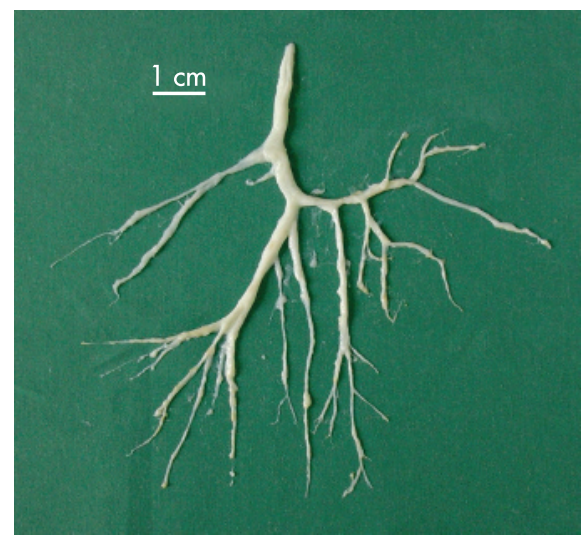

Figure 1 Expectorated bronchial cast. protein $(57.4 \mathrm{~g} / \mathrm{l})$, gammaglobulin $(4.4 \mathrm{~g} / \mathrm{l})$ and corrected calcium $(2.1 \mathrm{mmol} / \mathrm{l})$ levels were low. The patient had selective $\operatorname{IgG}_{1}$ deficiency (IgA $0.65 \mathrm{~g} / \mathrm{l}$, IgM $1.68 \mathrm{~g} / \mathrm{l}$, IgG $4.71 \mathrm{~g} / 1, \operatorname{IgG}_{1} 2.00 \mathrm{~g} / 1, \operatorname{IgG}_{2} 0.91 \mathrm{~g} / 1, \mathrm{IgG}_{3}$ $\left.0.34 \mathrm{~g} / 1, \mathrm{IgG}_{4} 0.09 \mathrm{~g} / \mathrm{l}\right)$. No activity against granulocyte/macrophage colony-stimulating factor was found in the blood, making alveolar proteinosis unlikely. The casts consisted mainly of protein and lipids and contained significant amounts of immunoglobulins (IgG $1.63 \mathrm{~g} / \mathrm{l}$, IgA $0.33 \mathrm{~g} / 1$, IgM $0.45 \mathrm{~g} / \mathrm{l})$. Histological examination revealed the presence of surfactant protein A, fibrin and epithelial cells. Electron microscopy showed crystalline structures typical of calcium deposits (fig 2) and cells containing lipid particles. We were unable to quantify the calcium content. Despite our therapeutic efforts the patient's condition is deteriorating slowly. Bronchial cast production remains and she is currently being evaluated for transplantation.
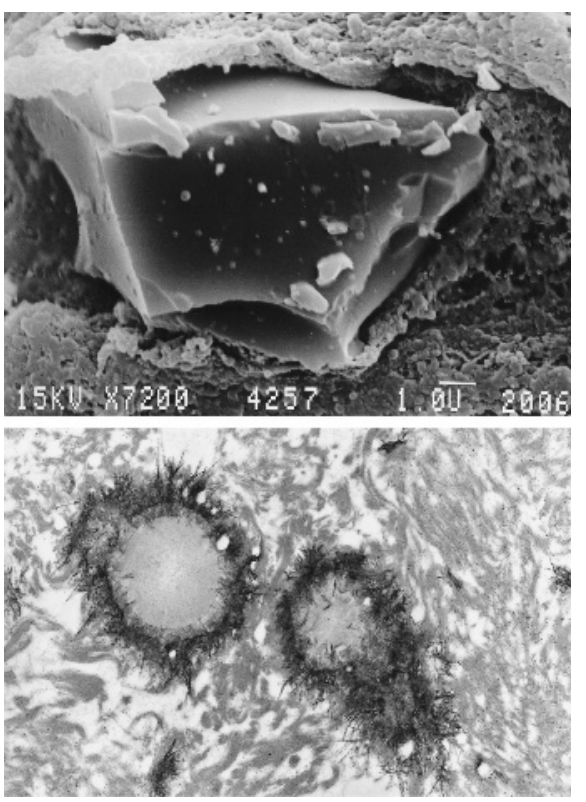

Figure 2 Scanning reflection electron microscopic photograph (top) and transmission electron microscopic photograph (bottom) of a calcium crystal.
Learning points

- This case illustrates the importance of long-term follow-up as diseases may evolve in unexpected ways.

- Despite initial histological evidence of fibrosing lung disease, it later appeared that other features of the disease (ie, continuous cast formation) were causing the symptoms.

- Treating a presumed but not proven diagnosis can lead to serious side effects aggravating the patient's symptoms. Both a weight gain of $>30 \mathrm{~kg}$ and the development of pulmonary tuberculosis is likely to be related to long-term steroid therapy.

\section{DISCUSSION}

Several cases of bronchial cast formation have been described, ${ }^{1-4}$ but the aetiology is rarely evident despite a long list of differential diagnoses. The association with bronchial loss of crystalline calcium and immunoglobulins has not previously been described. It remains unknown whether it is causal or casual. Unfortunately, we were unable to identify the underlying aetiology. Further studies will remain challenging due to the rarity of the disease.

\section{Herzmann, ${ }^{1}$ V Jansen, ${ }^{2} \mathrm{~J} \mathrm{Lichey}^{3}$ \\ ${ }^{1}$ Vivantes Auguste Viktoria Klinikum, Klinik für Kardiologie und Diabetologie, Berlin, Germany; ${ }^{2}$ Hospital Dienstleistung and Beratung $\mathrm{GmbH}$ - Laborverbund, Bernau, Germany; ${ }^{3}$ Evangelische Lungenklinik Berlin, Berlin, Germany}

Correspondence to: Dr C Herzmann, Vivantes Auguste Viktoria Klinikum, Klinik für Kardiologie und Diabetologie, Berlin 10829, Germany; christian.herzmann@web.de

Acknowledgements: The authors thank Professor Dr Welsch and staff at the Anatomical Institute II, Ludwig Maximilian University, Munich, Germany for electron microscopy.

\section{Competing interests: None. \\ Patient consent: Obtained.}

Author's contributions: $\mathrm{CH}$ : collecting data, literature research, writing of paper; $\mathrm{VJ}$ : laboratory work; JL: literature research.

\section{Thorax 2008;63:754. doi:10.1136/thx.2007.077396}

\section{REFERENCES}

. Fairshter RD, Riley CA, Hewlett RI. Large bronchial casts. Arch Intern Med 1979;139:522-5.

2. Hug MI, Ersch J, Moenkhoff M, et al. Chylous bronchial casts after fontan operation. Circulation 2001;103:1031-3.

3. Park JY, Elshami AA, Kang DS, et al. Plastic bronchitis. Eur Respir J 1996;9:612-4.

4. Studer SM, Terry PB. Images in clinical medicine. Bronchial cast. N Engl J Med 2002;346:981. 